\title{
A LEMBRANÇA DO PRESENTE E O FALSO RECONHECIMENTO ${ }^{1}$
}

\author{
Henri Bergson
}

Tradução: Jonas Gonçalves Coelho ${ }^{2}$

\section{Traços característicos}

A ilusão sobre a qual apresentaremos algumas considerações teóricas é bem conhecida. Enquanto se assiste a um espetáculo ou se participa de uma conversa, surge, de repente, a convicção de que já se viu o que se vê, já se ouviu o que se ouve, já se pronunciaram as frases que se pronunciam - que esteve aí, no mesmo lugar, nas mesmas disposições, sentindo, percebendo, pensando e querendo as mesmas coisas - enfim, de que se revive nos mínimos detalhes alguns instantes da vida passada. Algumas vezes, a ilusão é tão completa que a todo o momento, enquanto dura, acredita-se nela a ponto de predizer o que vai acontecer: como já não o saberíamos,

1 Este estudo apareceu na Revue philosophique de dezembro de 1908. Bergson desenvolve dois temas fundamentais de uma de suas mais importantes obras filosóficas, publicada onze anos antes, Matéria e memória. Primeiramente, trata da relação entre percepção e memória, procurando destacar a íntima relação entre essas duas "operações elementares do espírito" tanto na vigília quanto no sonho, com ênfase especial no papel desempenhado pela memória. Um dos aspectos do falso reconhecimento é o desdobramento da percepção em imagem percebida e lembrança, isto é, a percepção e a lembrança formam-se simultaneamente. A seguir, Bergson trata da noção de tensão psicológica, intimamente relacionada à noção de vontade, a partir da qual estabelece uma analogia entre o fenômeno do falso reconhecimento e o sonho e a diferença entre esses e a vigília. Entre o sonho e a vigília haveria todos os graus intermediários - aí se inclui o falso reconhecimento - de atenção à vida e de adaptação à realidade, ou seja, a redução do tom mental da vida psicológica é outra das origens do falso reconhecimento. A relevância desses dois temas deve ser considerada ao relembrarmos que para Bergson a memória e a vontade são os dois componentes fundamentais da personalidade humana e que o filósofo define o espírito ora como memória ora como vontade.

2 Professor Assistente Doutor de Filosofia do Departamento de Ciências Humanas da Unesp, campus de Bauru. 
uma vez que sentimos que teremos sabido? Não é raro, então, que se perceba o mundo exterior sob um aspecto singular, como em um sonho. Tornase estranho a si mesmo, a ponto de se desdobrar e de assistir como simples espectador ao que diz e ao que faz. Esta última ilusão, levada ao extremo, tornando-se "despersonalização", 3 não está indissoluvelmente ligada ao falso reconhecimento, embora tenha ligação com ele. Todos estes sintomas são mais ou menos acentuados. A ilusão, em vez de se desenhar em sua forma completa, apresenta-se freqüentemente como um esboço. Mas, esboço ou desenho acabado, ela tem sempre sua fisionomia original.

São muitas as observações sobre o falso reconhecimento: elas assemelham-se de maneira notável, sendo freqüentemente formuladas em termos idênticos. Temos nas mãos a auto-observação que um homem de letras, hábil em estudar a si mesmo, que não havia jamais ouvido falar da ilusão do falso reconhecimento e que acreditava ser o único a experimentá-la, redigiu para nós. Sua descrição compõe-se de uma dezena de frases: todas se encontram, mais ou menos tais e quais, nas observações já publicadas. Felicitamo-nos, inicialmente, por nela se haver, pelo menos, assinalado uma expressão nova: o autor nos diz que o que domina o fenômeno é uma sensação de "inevitabilidade", como se nenhuma potência do mundo pudesse deter as palavras e os atos que estão por vir. Mas eis que, relendo as observações recolhidas por M.Bernard-Leroy, encontramos em uma delas a mesma palavra: "Eu assistia a minhas ações; elas eram inevitáveis". ${ }^{4}$ Em verdade, pode-se perguntar se existe uma ilusão tão nitidamente estereotipada.

Não incluímos no falso reconhecimento algumas ilusões que têm algo em comum com ele, mas que dele diferem por seu aspecto geral. M.Arnaud descreveu em 1896 um caso notável que já estudava há três anos: durante esses três anos, o sujeito experimentou ou acreditou experimentar, continuamente, a ilusão de falso reconhecimento, imaginando reviver novamente toda a sua vida. ${ }^{5}$ Este caso não é aliás único; acreditamos que é preciso aproximá-lo de um caso já antigo de Pick, ${ }^{6}$ de uma observação de Kraepelin, ${ }^{7}$ e também da de Forel. ${ }^{8}$ A leitura dessas observações nos faz imediatamente pensar em alguma coisa muito diferente do falso reconhecimento. Não se trata mais de uma impressão brusca e curta, que surpreende por sua

3 A palavra foi criada por M.Dugas (Um caso de despersonalização, Revue philos., vol. XLV, 1898, pp.500-507).

4 L'illusion de fausse reconnaissance, Paris, 1898, p.176.

5 Arnaud, Un cas d'illusion de "déjà vu", Annales médico-psychologiques, $8^{\mathrm{a}}$ série, vol.III, 1896, pp. 455-470.

6 Arch. f. Psychiatrie, vol. VI, 1876, pp.568-574.

7 Arch. f. Psychiatrie, vol. XVIII, 1887, p.428.

8 Forel, Das Gedächtnis und seine Abnormitäten, Zurique, 1885, pp.44-45. 
estranheza. O sujeito acha, ao contrário, que o que ele experimenta é normal; por vezes necessita dessa impressão, procura-a quando ela lhe falta e crê, além disso, que ela é mais contínua do que é na realidade. Entretanto, ao olhar mais de perto, descobrem-se diferenças profundas. No falso reconhecimento, a lembrança ilusória não está jamais localizada em um ponto do passado; ela habita um passado indeterminado, o passado em geral. Aqui, ao contrário, os sujeitos atribuem freqüentemente datas precisas a suas pretensas experiências anteriores; eles são presas de uma verdadeira alucinação da memória. Observamos, além disso, que são todos alienados: o de Pick e os de Forel e Arnaud têm idéias delirantes de perseguição; o de Kraepelin é um maníaco, alucinado da visão e da audição. Talvez seja preciso aproximar seu problema mental daquele que foi descrito por Coriat sob o nome de paramnésia reduplicativa ${ }^{9}$ e que o próprio Pick, em um trabalho mais recente, chamou de "uma nova forma de paramnésia". ${ }^{10}$ Nesta última afecção, o sujeito acredita ter já vivido várias vezes sua vida atual. O doente de Arnaud tinha precisamente esta ilusão.

Mais delicada é a questão levantada pelos estudos de M.Pierre Janet sobre a psicastenia. Em oposição à maior parte dos autores, M.Janet faz do falso reconhecimento um estado nitidamente patológico, relativamente raro, vago e indistinto, no qual seria muito apressado ver uma ilusão específica da memória ${ }^{11}$ Tratar-se-ia, em realidade, de uma perturbação mais geral. Encontrando-se enfraquecida a "função do real", o sujeito não apreenderia completamente o atual; ele não sabe dizer exatamente se é o presente, o passado ou mesmo o futuro; ele decidir-se-á pelo passado quando se lhe tiver sugerido esta idéia pelas próprias questões que se lhe coloque. Ninguém contestará que a psicastenia, tão profundamente estudada por $\mathrm{M}$. Pierre Janet, seja o terreno no qual pode se desenvolver uma multidão de anomalias: o falso reconhecimento faz parte dessa categoria. E não contestará, também, o caráter psicastênico do falso reconhecimento em geral. Mas nada prova que este fenômeno, quando preciso, completo, nitidamente analisável em percepção e lembrança, quando, sobretudo, se produz em pessoas que não apresentam nenhuma outra anomalia, tenha a mesma estrutura interna que aquele que se esboça de forma vaga, no estado de simples tendência ou de virtualidade, nos espíritos que reúnem todo um conjunto de sintomas psicastênicos. Suponhamos em efeito que o falso reconhecimento propriamente dito - perturbação sempre passageira e sem

\footnotetext{
9 Journal of nervous and mental diseases, 1904, vol. XXXI, pp.577-587 e 639-659.

10 Jahrb. f. Psychiatrie u. Neurologie, vol. XV, 1901, pp.1-35.

11 P.Janet, Les obsessions et la psychastenie, 1903, vol. I, p.287 ss. A propósito do "déjà vu", cf. Journal de Psychologie, vol. II, 1905, pp.139-166.
} 
gravidade - seja um meio imaginado pela natureza para localizar em um certo ponto, limitar a alguns instantes e reduzir assim à sua forma mais benigna uma certa insuficiência que, estendida e diluída no conjunto da vida psicológica, seria a psicastenia: dever-se-á esperar que esta concentração sobre um ponto único dê ao estado da alma resultante uma precisão, uma complexidade e, sobretudo, uma individualidade que não existe nos psicastênicos em geral, capazes de converter em falso reconhecimento vago, como em muitos outros fenômenos anormais, a insuficiência radical que eles sofrem. A ilusão constituiria, pois, uma entidade psicológica distinta, diferentemente do que acontece com os psicastênicos. Mas nada do que se diz desta ilusão nos psicastênicos deveria ser rejeitado.

Resta, ainda, perguntar por que e como se cria o sentimento do "dejà vu"12 nos casos -que acreditamos serem muito numerosos, - nos quais se afirma com muito clareza que há uma percepção presente e uma percepção passada idênticas. Não esqueçamos que muitos daqueles que estudaram o falso reconhecimento, Jensen, Kraepelin, Bonatelli, Sander, Anjel, etc., o experimentaram em si mesmos. Não se limitaram a recolher observações; anotaram, como psicólogos de profissão, o que experimentaram. Ora, todos estes autores concordam em descrever o fenômeno como um recomeço bem nítido do passado, como um fenômeno duplo que seria percepção por um lado e lembrança por outro, - e não como um fenômeno de face única, um estado cuja realidade parecesse simplesmente flutuar, destacado do tempo, percepção ou lembrança, à vontade. Assim, sem nada sacrificar do que M.Janet nos ensinou a respeito dos psicastênicos, teremos que procurar uma explicação especial do fenômeno propriamente dito do falso reconhecimento. ${ }^{13}$

\section{Teorias explicativas}

Onde encontrar esta explicação?

Poder-se-ia, inicialmente, sustentar que o falso reconhecimento nasce da identificação da percepção atual com uma percepção anterior efetivamente parecida em seu conteúdo ou pelo menos em sua nuança afetiva. Esta percepção anterior pertenceria à vigília, segundo alguns autores

12 N.T. Optamos por manter no corpo do texto a expressão em francês "déjà vu" de uso familiar entre os falantes da língua portuguesa. Não traduzimos também a outra expressão utilizada por Bergson, o "déjà vécu". A tradução literal é, respectivamente, "já visto" e "já vivido".

13 É preciso observar que a maior parte dos autores considera o falso reconhecimento como uma ilusão muito difundida. Wigan pensava que todo mundo está sujeito a ele. Kraepelin diz que é um fenômeno normal. Jensen pretende que não há quase nenhuma pessoa, que, prestando atenção a si mesma, não conheça essa ilusão. 
(Sander, ${ }^{14}$ Höffding, ${ }^{15}$ Le Lorrain, ${ }^{16}$ Bourdon, ${ }^{17}$ Bélugou ${ }^{18}$ ), ao sonho, segundo outros (James Sully, ${ }^{19}$ Lapie, ${ }^{20}$ etc.), à vigília ou ao sonho, mas sempre ao inconsciente, segundo Grasset. ${ }^{21}$ Em todos os casos, quer se trate da lembrança de uma coisa vista ou da lembrança de uma coisa imaginada, haveria evocação confusa ou incompleta de uma lembrança real. ${ }^{22}$

Esta explicação pode ser aceita nos limites em que a encerram vários autores que a propõem. ${ }^{23}$ Ela se aplica, de fato, a um fenômeno parecido, em alguns aspectos, com o falso reconhecimento. Aconteceu a todos nós perguntar, em presença de um espetáculo novo, se já o havíamos. Refletindo, encontramos uma percepção anterior análoga, que apresentava alguns traços comuns com a experiência atual. Mas o fenômeno do qual se trata aqui é muito diferente. As duas experiências parecem rigorosamente idênticas e sentimos que nenhuma reflexão conduziria esta identidade a uma vaga semelhança, porque não estamos simplesmente diante do "déjà vu": é mais do que isto, é o "déjà vécu" que experienciamos. Acreditamos tratarse do recomeço integral de um ou de vários minutos de nosso passado, com a totalidade de seu conteúdo representativo, afetivo, ativo. Kraepelin, que insistiu sobre essa primeira diferença, assinala ainda uma outra. ${ }^{24} \mathrm{~A}$ ilusão do falso reconhecimento estabelece-se instantaneamente no sujeito, e instantaneamente também o abandona, deixando atrás de si uma impressão de sonho. Nada de semelhante à confusão mais ou menos lenta de se estabelecer, mais ou menos fácil de se dissipar, de uma experiência atual com uma experiência anterior semelhante a ela. Acrescentemos (e isto talvez seja o essencial) que esta confusão é um erro como os outros erros, um fenômeno localizado no domínio da inteligência pura. Ao contrário, o falso reconhecimento pode abalar a personalidade inteira. Ele interessa à sensibilidade e à vontade tanto quanto à inteligência. Quem o experimenta é fre-

14 Arch. F. Psychiatrie, vol. IV, 1874, pp.244-253.

15 Höffding, Psychologie, pp.166-167.

16 Le Lorrain, A propos de la paramnésie, Rev. Philosophique, vol. XXXVII, 1894, pp.208-210.

17 Bourdon, Sur la reconaissance des phénomènes nouveaux, Rev. Philos., vol. XXXVI, 1893, pp.629631. Aí não está aliás senão uma parte da tese de M.Bourdon.

18 Bélugou, Sur un cas de paramnésie, Rev. philos., vol. LXIV, 1907, pp.282-284. M.Bélugou distingue aliás duas espécies de paramnesia.

19 J. Sully, Les illusions des sens et de l'esprit, p.198.

20 Lapie, Note sur la paramnésie, Rev. philos., vol. XXXVII, 1894, pp.351-352.

21 Grasset, La sensation du "déjà vu", Journal de Psychologie, janeiro 1904, pp.17-27.

22 A idéia de uma semelhança de coloração afetiva pertence mais particularmente à M.Boirac, Rev. philos., 1876. V.I, p.431.

23 Ribot e William James, que pensaram em uma explicação desse gênero, tiveram o cuidado de acrescentar que eles a propunham apenas para alguns casos (Ribot, Les maladies de la memóire, 1881, p.150; William James, Principies of psychology, vol. I, p.675, nota).

24 Arch. F. Psychiatrie, vol. XVIII, 1887, pp.409-436. 
qüentemente tomado por uma emoção característica: torna-se mais ou menos estranho a si mesmo e como que "automatizado". Encontramo-nos, aqui, diante de uma ilusão que compreende elementos diversos e que os organiza em um único efeito simples, verdadeira individualidade psicológica. ${ }^{25}$

Onde se deve procurar o seu centro? Será em uma representação, em uma emoção, ou em um estado da vontade?

A primeira tendência é a das teorias que explicam o falso reconhecimento por uma imagem, nascida no curso da percepção ou um pouco antes, e lançada imediatamente no passado. Para dar conta desta imagem, supôsse inicialmente que o cérebro fosse duplo, que produzisse duas percepções simultâneas, que uma podia, em certos casos, estar atrasada em relação à outra e, em razão de sua intensidade mais fraca, parecer uma lembrança (Wigan, ${ }^{26}$ Jensen $^{27}$ ). Fouillée ${ }^{28}$ também falou de uma "falta de sinergia e de simultaneidade nos centros cerebrais", de onde nasceria uma "diplopia", "um fenômeno patológico de eco e de repetição interior". A psicologia procura hoje se afastar destes esquemas anatômicos; a hipótese de uma dualidade cerebral foi completamente abandonada. Resta, então, a noção de que a segunda imagem seja alguma coisa da própria percepção. Para Anjel, é preciso distinguir dois aspectos em toda percepção: de um lado, a impressão bruta produzida na consciência; de outro, a apropriação desta impressão pelo espírito. Ordinariamente, os dois processos se recobrem; mas, se o segundo acontece atrasado, segue-se uma imagem dupla, que dá lugar ao falso reconhecimento. ${ }^{29}$ M.Piéron propôs uma idéia análoga. ${ }^{30}$ Para M.Lalande, ${ }^{31}$ seguido por M.Arnaud, ${ }^{32}$ um espetáculo pode produzir em nós uma primeira impressão, instantânea e pouco consciente, à qual sucede uma distração de alguns segundos, estabelecendo-se na seqüência a percepção normal. Se, neste último momento, a impressão primeira retorna, ela produz em nós o efeito de uma lembrança vaga, não localizável no tempo, e temos o falso reconhecimento. Myers propõe uma explicação não menos engenhosa, fundada sobre a distinção entre o eu consciente e o eu "subliminar": o primeiro recebe de uma cena a que assiste apenas uma impressão global,

25 A hipótese de Grasset, segundo a qual a primeira experiência teria sido registrada pelo inconsciente, escaparia, a rigor, às duas últimas objeções, mas não à primeira.

26 A-L. Wigan, A new view of insanity : the duality of the mind, Londres, 1884, p.85.

27 Allg. Zeitscher. f. Psychiatrie, vol. XXV, 1868, pp.48-63.

28 Fouillée, La mémoire et la reconnaissance des souvenirs, Revue des Deux Mondes, 1885, vol. LXX, p.154.

29 Arch. f. Psychiatrie, vol. VIII, 1878, pp.57-64.

30 Piéron, Sur l'interprétation des faits de paramnésie, Rev. philos., vol. LIV, 1902, pp.160-163.

31 Lalande, Des paramnésies, Rev. Philos., vol. XXXVI, 1893, pp.485-497.

32 Arnaud, Un cas d'illusion du "déjà vu" ou de "fausse mémoire", Annales médico-psychologiques, $8^{a}$ série, vol. III, p.455. 
cujos detalhes sempre estão um pouco atrasados em relação aos do excitante exterior; o segundo fotografa estes detalhes sucessivamente, instantaneamente. Este último está, pois, adiantado em relação à consciência e, se se manifesta a ela bruscamente, lhe traz uma lembrança daquilo que ela se ocupa em perceber. ${ }^{33}$ M.Lemaître adotou uma posição intermediária entre as de Lalande e de Myers. ${ }^{34}$ Antes de Myers, M.Dugas propôs a hipótese de um desdobramento da pessoa. ${ }^{35}$ Enfim, faz muito tempo que Ribot deu à tese das duas imagens uma força muito grande, supondo uma espécie de alucinação consecutiva à percepção e mais intensa que ela: a alucinação lançaria a percepção ao segundo plano com o caráter fugaz das lembranças. ${ }^{36}$

Não podemos empreender aqui o exame aprofundado que cada uma destas teorias exige. Limitemo-nos a dizer que aceitamos o seu princípio: acreditamos que o falso reconhecimento implica a existência real, na consciência, de duas imagens, sendo uma a reprodução da outra. A grande dificuldade, a nosso ver, é explicar simultaneamente porque uma das duas imagens é lançada no passado e porque a ilusão é continua. Se se considera a imagem lançada no passado como anterior à imagem localizada no presente, se se vê nela uma primeira percepção menos intensa, ou menos atenta, ou menos consciente, tenta-se pelo menos, nos fazer compreender porque ela toma a forma de uma lembrança; mas trata-se, nesse caso, apenas da lembrança de um certo momento da percepção; a ilusão não se prolongará, não se renovará através da percepção inteira. Se, ao contrário, as duas imagens se formam conjuntamente, compreende-se melhor a continuidade da ilusão, mas o arremesso de uma delas no passado exige, mais imperiosamente ainda, uma explicação. Poder-se-ia, aliás, perguntar-se se alguma das hipóteses, mesmo do primeiro gênero, dá realmente conta desse arremesso, e se a fraqueza ou a subconsciência de uma percepção basta para lhe dar o aspecto de uma lembrança. Qualquer que seja uma teoria do falso reconhecimento, ela deve responder ao mesmo tempo às duas exigências que acabamos de formular, e estas duas exigências parecerão inconciliáveis, acreditamos, enquanto não se tiver aprofundado, do ponto de vista puramente psicológico, a natureza da lembrança normal.

Escapar-se-á da dificuldade negando a dualidade das imagens, invocando um "sentimento intelectual" do "déjà vu", que viria, por vezes, se sobrepor à nossa percepção do presente e nos fazer crer em um recomeço do passado? Tal é a idéia proposta por M.E.Bernard-Leroy em um livro bem co-

\footnotetext{
33 Meyers, The subliminal self, Proc. Of the Society for psychical research., vol. XI, 1895, p.343.

34 Lemaitre, Des phénomènes de paramnésie, Archives de psychologie, vol. III, 1903, pp.101-110.

35 Dugas, Sur la fausse mémoire, Rev. philoso., vol. XXXVII, 1894, pp.34-35.

36 Ribot, Les maladies de la mémoire, p.152.
} 
nhecido. ${ }^{37}$ Estamos prontos para concordar com a sua tese de que o reconhecimento do presente se faz o mais freqüentemente sem nenhuma evocação do passado. Nós mesmos mostramos que a "familiaridade" dos objetos da experiência diária relaciona-se ao automatismo das reações que eles provocam e não à presença de uma lembrança-imagem que viria duplicar a imagem-percepção. ${ }^{38}$ Mas este sentimento de "familiaridade" não é seguramente o que intervém no falso reconhecimento, e o próprio M.Bernard-Leroy tomou o cuidado de os distinguir um do outro. ${ }^{39}$ Resta, então, que o sentimento do qual falam. Bernard-Leroy seja aquele que se experimenta quando se diz, ao cruzar com uma pessoa na rua, que já se deve têla encontrado. Mas, inicialmente, este último sentimento está, sem dúvida, inseparavelmente ligado a uma lembrança real, a da pessoa ou de uma outra parecida: talvez seja apenas a consciência vaga e quase extinta dessa lembrança junto com um esforço nascente e impotente para a reviver. Em seguida, é preciso observar o que se diz dela em tal caso: "Eu vi esta pessoa em algum lugar"; não se diz: "Eu vi esta pessoa aqui, nas mesmas circunstâncias, em um momento de minha vida que era indistinguível do momento atual". Supondo, pois, que o falso reconhecimento tenha sua raiz em um sentimento, este sentimento é único em seu gênero e não pode ser aquele do reconhecimento normal, vagando pela consciência e se enganando de destinação. Sendo especial, ele deve relacionar-se a causas especiais, as quais precisam ser determinadas.

Restaria, enfim, procurar a origem do fenômeno na esfera da ação antes que na do sentimento ou da representação. Tal é a tendência das mais recentes teorias do falso reconhecimento. Assinalamos já há muitos anos a necessidade de se distinguirem graus diversos de tensão ou de tom na vida psicológica. Dizíamos que a consciência é tanto mais equilibrada quanto mais tensa na direção da ação, tanto mais instável quanto mais distendida em uma espécie de sonho; que entre estes dois planos extremos, o plano da ação e o plano do sonho, há todos os planos intermediários correspondentes a tantos graus decrescentes de "atenção à vida" e de adaptação à realidade. ${ }^{40}$ As idéias que apresentamos a esse respeito foram acolhidas com certa reserva; alguns as julgaram paradoxais. Elas se chocavam, em efeito, com as teorias geralmente aceitas, com a concepção atomística da vida mental.

37 E.Bernard-Leroy, L'illusion de fausse reconnaissance, Paris, 1898. A leitura deste livro, que contém um grande número de observações inéditas, é indispensável a quem quiser ter uma idéia precisa do falso reconhecimento. - Em seu Étude sur les illusions du temps des rêves, tese de medicina, Paris, 1900, Mlle J. Tobolowska adota as conclusões de M.Bernard-Leroy.

38 Matière et mémoire, Paris, 1896, p.93 ss.

39 Op.cit., p.24.

40 Matière et Mémoire, Paris, 1896, em particular pp.184-195. 
Todavia, a psicologia se aproxima delas cada vez mais, sobretudo desde que M.Pierre Janet chegou, por vias diferentes, a conclusões totalmente compatíveis com as nossas. É, pois, em uma redução do tom mental que se procurará a origem do falso reconhecimento. Para M.Pierre Janet, esta redução produziria diretamente o fenômeno, diminuindo o esforço de síntese que acompanha a percepção normal: esta adquiriria, então, o aspecto de uma vaga lembrança, ou de um sonho. ${ }^{41}$ Mais precisamente, haveria aqui apenas um desses "sentimentos de incompletude" que M.Janet estudou de maneira tão original: o sujeito, confuso pelo que há de incompletamente real e, conseqüentemente, de incompletamente atual em sua percepção, não sabe muito bem se ela se relaciona ao presente, ao passado ou mesmo ao futuro. M.Léon-Kindberg retomou e desenvolveu esta idéia de uma diminuição do esforço de síntese. ${ }^{42}$ Já Heymans tentou mostrar como uma "redução da energia psíquica" poderia modificar o aspecto de nosso ambiente habitual e comunicar o aspecto do "déjà vu" aos acontecimentos que nele se sucedem. "Suponhamos, diz ele, que nosso ambiente habitual não faça mais que ressoar muito baixo as associações regularmente despertadas algures por ele. Acontecerá precisamente o que acontece nos casos em que, após muitos anos, vemos novamente os lugares ou os objetos, ouvimos novamente as melodias que conhecíamos outrora, mas que havíamos há muito tempo esquecido... Ora, se nesses últimos casos, aprendemos a interpretar o mais fraco impulso das associações como o sinal de experiências anteriores relacionadas aos mesmos objetos que os do presente, adivinhase que, nos outros casos também, nos casos em que, em conseqüência de uma diminuição da energia psíquica, o ambiente habitual manifesta uma eficácia associativa muito diminuída, teremos a impressão de que nele se repetem, identicamente, os acontecimentos pessoais e as situações tiradas do fundo de um passado nebuloso". ${ }^{43}$ Enfim, em um trabalho aprofundado que contém, sob a norma de auto-observação, uma das mais penetrantes análises já feitas do falso reconhecimento, ${ }^{44} \mathrm{MM}$.Dromard e Albès explicam o fenômeno como uma diminuição do "tônus da atenção" a qual conduziria a uma ruptura entre o "psiquismo inferior" e o "psiquismo superior". O primeiro, funcionando sem a ajuda do segundo, perceberia automaticamente

41 P.Janet, Les obsessions et la psychasthénie, vol. I, Paris, 1903, p.287 ss. Cf. A propos du déjà vu, Journal de Psychologie, vol. II, 1905, pp.289-307.

42 Léon-Kindberg, Le sentiment du déjà vu et l'illusion de fausse reconnaissance, Revue de psychiatrie, 1903, pp.139-166.

43 Zeitschr. f. Psychologie, vol. XXXVI, 1904, pp.321-343.

44 Dromard e Albès, Essai théorique sur l'illusion dite de fausse reconnaissance, Journal de psychologie, vol. II, 1904, pp.216-228. 
o objeto presente, e o segundo empregar-se-ia inteiramente a considerar a imagem recolhida pelo primeiro, em vez de olhar o próprio objeto. ${ }^{45}$

Diremos dessas últimas teses o que dissemos das primeiras, ou seja, que aceitamos o seu princípio: é em uma redução do tom geral da vida psicológica que é preciso procurar a causa inicial do falso reconhecimento. $\mathrm{O}$ ponto delicado é determinar a forma especial que reveste aqui a desatenção à vida e também explicar por que ela acaba por nos fazer tomar o presente por uma repetição do passado. Um simples relaxamento do esforço de síntese exigido pela percepção dará à realidade o aspecto de um sonho, mas por que este sonho aparece como a repetição integral de um minuto já vivido? Supondo que o "psiquismo superior" intervenha para sobrepor sua atenção a esta percepção desatenta, ter-se-á, quando muito, uma lembrança considerada atenta: não será uma percepção duplicada de uma lembrança. Enquanto que uma preguiça da memória associativa, como a que supõe Heymans, simplesmente tornaria penoso o reconhecimento do ambiente: longe desse reconhecimento penoso do familiar, há a lembrança de uma experiência anterior determinada, idêntica em todos os pontos à experiência atual. Em suma, parece que é preciso combinar este último sistema de explicação com o primeiro, admitir que o falso reconhecimento refere-se, ao mesmo tempo, a uma diminuição da tensão psicológica e a um desdobramento da imagem, e procurar o que deve ser a diminuição para produzir o desdobramento, o que é o desdobramento se ele traduz uma simples diminuição. Mas não se trata de aproximar artificialmente uma teoria da outra. A aproximação dar-se-á por si mesma, acreditamos, se se aprofundar, nas duas direções indicadas, a compreensão do mecanismo da memória.

\section{Princípio de explicação proposto}

Gostaríamos de fazer, inicialmente, uma observação geral a respeito dos fatos psicológicos patológicos ou anormais. Dentre esses fatos, há os que estão evidentemente relacionados a um empobrecimento da vida normal. Tais são as anestesias, as amnésias, as afasias, as paralisias, enfim, todos os estados caracterizados pela abolição de algumas sensações, de algumas lembranças ou de alguns movimentos. Para definir estes estados, indicar-se-á, pura e simplesmente, o que desapareceu da consciência. Eles consistem em uma ausência. Todo mundo verá neles um déficit psicológico.

Ao contrário, existem estados patológicos ou anormais que parecem se sobrepor à vida normal e a enriquecer em vez de a diminuir. Um delírio, uma

45 É igualmente por uma "redução do tom vital" que se explicou a "despersonalização". Ver, a este respeito, Dugas, Un cas de dépersonnalisation, Rev. philos., vol. XLV, 1898, pp.500-507. 
alucinação, uma idéia fixa são fatos positivos. Eles consistem na presença, e não na ausência, de alguma coisa. Eles parecem introduzir no espírito algumas maneiras novas de sentir e de pensar. Para defini-los, é preciso considerar o que são e o que trazem, em vez de prender-se ao que não são e ao que levam. Se a maior parte dos sintomas da alienação mental pertence a esta segunda categoria, poder-se-ia dizer o mesmo de muitas das anomalias e singularidades psicológicas, dentre elas, o falso reconhecimento. Como veremos mais adiante, ele apresenta um aspecto sui generis, que o diferencia do reconhecimento verdadeiro.

Todavia, o filósofo pode se perguntar se, no domínio do espírito, a doença e a degenerescência são realmente capazes de criar alguma coisa, e se os caracteres aparentemente positivos, que dão ao fenômeno anormal um aspecto de novidade, não se reduziriam, quando se aprofunda a sua natureza, a um vazio interior, a um déficit do fenômeno normal. Concordar-se-á em dizer que a doença é uma diminuição. É verdade que esta é uma maneira vaga de se exprimir e que seria preciso indicar com precisão, nos casos onde nada de visível desapareceu da consciência, no que a consciência diminuiu. Esboçamos outrora uma tentativa desse gênero, como o lembramos há pouco. Dizíamos que ao lado da diminuição do número de estados de consciência, há uma outra que se refere à sua solidez ou a seu peso. No primeiro caso, a doença elimina pura e simplesmente alguns estados sem tocar nos outros. No segundo, nenhum estado psicológico desaparece, mas todos são atingidos, todos perdem sua base, isto é, sua força de inserção e de penetração na realidade. ${ }^{46}$ É a "atenção à vida" que diminuiu, e os fenômenos novos que aparecem são apenas o aspecto exterior deste desinteresse.

Reconhecemos que, mesmo sob esta forma, a idéia é ainda muito geral para satisfazer os detalhes das explicações psicológicas. Pelo menos ela indicará o caminho a seguir para encontrar a explicação.

Se ela é aceita, não haverá lugar para procurar uma causa ativa que produza o fenômeno patológico ou anormal que se apresenta com características especiais, porque esse fenômeno, apesar das aparências, não tem nada de positivo, nada de novo. Ele já se produzia em tempo normal, mas estava impedido de aparecer no momento em que quisesse, devido a um desses mecanismos antagonistas, constantemente ativos, que asseguram a atenção à vida. É que a vida psicológica normal, tal como a representamos, é um sistema de funções no qual cada uma tem seu dispositivo particular. Cada dispositivo, entregue a si mesmo, produziria uma multidão de efeitos inúteis ou incômodos, capazes de perturbar o funcionamento dos outros e

46 Ver Matière et Mémoire, Paris, 1896, cap.III, em particular pp.192-193. 
de também desordenar nosso equilíbrio móvel, nossa adaptação constantemente renovada à realidade. Mas um trabalho de eliminação, de correção, de regulagem, persegue-se sem cessar, de onde resulta precisamente a saúde moral. Aí onde ele enfraquece, aparecem os sintomas que, acreditamos, criados para a circunstância, mas que, em realidade, sempre estiveram aí, ou, pelo menos, teriam estado, se tivéssemos deixado. Certamente, é natural que o teórico seja tocado pelo caráter sui generis dos fatos patológicos. Como esses fatos são complexos e apresentam uma certa ordem em sua complicação, seu primeiro movimento é o de os relacionar a uma causa ativa, capaz de organizar os seus elementos. Mas, se no domínio do espírito, a doença não tem força para criar alguma coisa, ela só pode consistir no afrouxamento ou na suspensão de alguns mecanismos que, no estado normal, impediam os outros de produzir seu pleno efeito. De sorte que a tarefa principal da Psicologia não seria explicar como tais ou quais fenômenos se produzem na doença, mas por que não se os constata no homem sadio.

Já consideramos por esse viés os fenômenos do sonho. Vêem-se, geralmente, nos sonhos fantasmas que se sobrepõem às percepções e concepções sólidas da vigília, fogos-fátuos que flutuam acima dela. Esses seriam fatos de uma ordem particular, que deveriam ser estudados em um capítulo à parte pela Psicologia que deles não mais se ocuparia. E é natural que pensemos assim, porque o estado de vigília é aquele que nos importa praticamente, enquanto que o sonho é o que há no mundo de mais estranho à ação, de mais inútil. Como, do ponto de vista prático, é um acessório, somos levados a encará-lo, do ponto de vista teórico, como um acidente. Afastemos essa idéia preconcebida e o estado de sonho nos aparecerá, ao contrário, como o substratum de nosso estado normal. Ele não se sobrepõe à vigília: é a vigília que se obtém pela limitação, concentração e tensão de uma vida psicológica difusa, que é a vida do sonho. Em um certo sentido, a percepção e a memória que se exercem no sonho são mais naturais que na vigília: a consciência se entretém nele em perceber por perceber, em lembrar por lembrar, sem nenhuma preocupação vital, quero dizer, com a ação a realizar. Já estar desperto consiste em eliminar, em escolher, em reunir sem cessar a totalidade da vida difusa do sonho em um ponto no qual um problema prático se coloca. Estar desperto significa querer. Cesse de querer, afastese da vida, desinteresse-se: você passará do eu da vigília para o eu dos sonhos, menos tenso, mas mais estendido que o outro. O mecanismo da vigília é, pois, o mais complexo, o mais delicado, o mais positivo também dos dois, e é a vigília, bem mais que o sonho, que exige uma explicação.

Mas, se o sonho imita em todos os aspectos a alienação mental, poderse-á aplicar a muitos fatos da alienação o que dissemos sobre o sonho. Não gostaríamos de abordar o estudo desses fenômenos com concepções muito sistemáticas. É duvidoso que se possa explicar todos eles da mesma manei- 
ra. E, para muitos dentre eles, ainda mal definidos, não é ainda o momento de tentar uma explicação. Como anunciamos inicialmente, apresentamos nossa tese a título de simples indicação metodológica, sem outro objetivo que o de orientar em um certo sentido a atenção do teórico. Todavia, existem fatos patológicos ou anormais aos quais ela pode ser aplicada desde já. Na primeira linha figura o falso reconhecimento. Sendo tal o mecanismo da percepção, e tal, a nosso ver, o da memória, o falso reconhecimento resultaria naturalmente do jogo dessas duas faculdades se um mecanismo especial não interviesse de imediato para o anular. A questão importante não é saber por que ele surge em certos momentos, em certas pessoas, mas por que ele não se produz em todos a todo instante.

\section{Como se forma a lembrança}

Vejamos como se forma a lembrança. Mas entendamos bem: a lembrança da qual falaremos é sempre um estado psicológico, ora consciente, ora semiconsciente, o mais freqüentemente inconsciente. Explicamos em outro lugar o que seria a lembrança como um traço deixado no cérebro. Dizíamos que as diversas memórias são localizáveis no cérebro, no sentido de o cérebro possuir para cada categoria de lembranças um dispositivo especial, destinado a converter a lembrança pura em percepção ou imagem nascentes: se se for mais longe, se se pretender determinar para cada lembrança o seu lugar na matéria cerebral, se se restringir a traduzir os fatos psicológicos incontestes em uma linguagem anatômica contestável, chegar-se-á a conseqüências desmentidas pela observação. Para dizer a verdade, quando falamos de nossas lembranças, pensamos em alguma coisa que nossa consciência possui ou que ela pode sempre recuperar, por assim dizer, puxando o fio que ela possui: a lembrança vai e vem, em efeito, do consciente ao inconsciente, e a transição entre os dois estados é tão contínua, o limite tão pouco demarcado, que não temos qualquer direito de supor uma diferença radical de natureza entre eles. É, pois, da lembrança que nos ocuparemos. Convencionamos, assim, para abreviar, dar o nome de percepção a toda consciência de alguma coisa presente, tanto à percepção interna quanto à percepção externa. Pretendemos que a formação da lembrança nunca é posterior à da percepção; ela lhe é contemporânea. À medida que se cria a percepção, a lembrança se projeta ao seu redor, como a sombra ao lado do corpo. Mas a consciência normalmente não a percebe, do mesmo modo que nosso olho não veria nossa sombra se a iluminasse cada vez que se volta para ela.

Suponhamos que a lembrança não seja criada durante a própria percepção. Pergunto: em que momento nascerá? Ela espera, para surgir, que a percepção desapareça? É o que geralmente se admite de forma implícita, 
quer se faça da lembrança inconsciente um estado psicológico, quer se a veja como uma modificação cerebral. Haveria, inicialmente, o estado psicológico presente; depois, quando ele não existe mais, a lembrança desse estado ausente. Haveria, inicialmente, a entrada em cena de algumas células, e isso seria a percepção, depois um traço deixado nessas células após o desaparecimento da percepção, e isso seria a lembrança. Mas, para que a coisa se passe dessa maneira, seria preciso que o curso de nossa existência consciente se compusesse de estados bem distintos, cada um dos quais, objetivamente, com um começo e um fim. Como não ver que essa divisão de nossa vida psicológica em estados, como a de uma comédia em cenas, não tem nada de absoluto, que ela é relativa à nossa interpretação, diversa e variável, de nosso passado? Segundo o ponto de vista em que me coloco, segundo o centro de interesse que escolhi, recorto diversamente o meu dia de ontem, e nele percebo grupos diferentes de situações ou de estados. Embora essas divisões não sejam todas igualmente artificiais, nenhuma existia em si, porque o desenrolar da vida psicológica é continuo. A tarde que acabo de passar no campo com meus amigos é decomposta em almoço + passeio + jantar, ou em conversação + conversação + conversação, etc.; e de nenhuma dessas conversações, que se sobrepõem umas às outras, se pode dizer que forma uma entidade distinta. Vinte sistemas de desarticulação são possíveis; nenhum sistema corresponde a articulações nítidas da realidade. Com que direito supor que a memória escolhe um deles, divide a vida psicológica em períodos distintos, espera o fim de cada período para ajustar-se com a percepção?

Alegar-se-á que a percepção de um objeto exterior começa quanto ele aparece, termina quando ele desaparece, e que se pode bem indicar, nesse caso pelo menos, um momento preciso no qual a lembrança substitui a percepção. Isso seria esquecer que a percepção se compõe ordinariamente de partes sucessivas, e que essas partes não têm nem mais nem menos individualidade que o todo. De cada uma se tem o direito de dizer que seu objeto desaparece sucessivamente. Como a lembrança nasceria apenas após o término de tudo? E como a memória saberia, em um momento qualquer da operação, que não está tudo terminado, que resta ainda alguma coisa?

Quanto mais se refletir sobre isso, mais se compreenderá que a lembrança não poderá jamais nascer se ela não se cria na medida em que ocorre a própria percepção. Ou o presente não deixa nenhum traço na memória, ou ele se desdobra a todo instante, em seu próprio jorro, em dois jatos simétricos, dos quais um recai no passado enquanto o outro se lança no futuro. Esse último, que chamamos percepção, é o único que nos interessa. Não precisamos da lembrança das coisas enquanto temos as próprias coisas. Se a consciência prática afasta essa lembrança como inútil, a reflexão teórica a considera inexistente. Assim, nasce a ilusão de que a lembrança sucede à percepção. 
Mas essa ilusão tem uma outra fonte ainda mais profunda.

A lembrança revivida, consciente, nos faz sentir que é a própria percepção que ressuscita sob uma forma mais modesta, e nada além dessa percepção. Entre a percepção e a lembrança haveria uma diferença de intensidade ou de grau, mas não de natureza. Definindo-se a percepção como um estado forte e a lembrança como um estado fraco, e se a lembrança de uma percepção só pode ser então essa percepção enfraquecida, parece-nos que a memória deva esperar, para registrar uma percepção no inconsciente, que a percepção adormeça em lembrança. Eis por que julgamos que a lembrança de uma percepção não poderia se criar com esta percepção nem se desenvolver ao mesmo tempo em que ela.

Mas a tese que faz da percepção presente um estado forte e da lembrança reavivada um estado fraco, que quer que se passe dessa percepção para aquela lembrança pela via da diminuição, tem contra si a observação mais elementar, como mostramos em um trabalho anterior. Tome uma sensação intensa e a faça decrescer progressivamente até zero. Se há entre a lembrança da sensação e a própria sensação apenas uma diferença de grau, a sensação tornar-se-á lembrança antes de se extinguir. Ora, chega um momento, sem dúvida, que não se pode mais dizer se se trata de uma sensação fraca que se experimenta ou de uma sensação fraca que se imagina, mas jamais o estado fraco torna-se lembrança, lançada no passado, do estado forte. A lembrança é, pois, outra coisa.

A lembrança de uma sensação é capaz de sugerir esta sensação, quero dizer, de a fazer renascer, fraca de início, mais forte em seguida, cada vez mais forte à medida que a atenção se fixa mais sobre ela. Mas ela é distinta do estado que sugere, e é precisamente porque a sentimos por detrás da sensação sugerida, como o magnetizador por detrás da alucinação provocada, que localizamos no passado a causa do que experimentamos. A sensação, com efeito, é essencialmente atual e presente; mas a lembrança, que a sugere do fundo do inconsciente de onde ela emerge com dificuldade, apresenta-se com essa força sui generis de sugestão que é a marca do que não é mais, do que ainda quer ser. Apenas quando a sugestão tiver tocado a imaginação é que a coisa sugerida se esboça em estado nascente, e eis por que é tão difícil distinguir entre uma sensação fraca que se experimenta e uma sensação fraca que se rememora sem uma data. Mas a sugestão não é em nenhum grau o que ela sugere, a lembrança pura de uma sensação ou de uma percepção não é em nenhum grau a própria sensação ou percepção. Ou então será preciso dizer que a palavra que o magnetizador usa para sugerir aos sujeitos adormecidos que eles têm açúcar ou sal na boca deva ser ela mesma um pouco açucarada ou salgada.

Escavando, ainda, abaixo dessa ilusão, encontrar-se-ia, em sua raiz, a necessidade, inata em nosso espírito, de se representar o todo de nossa vida 
interior, segundo o modelo da parte muito pequena de nós mesmos que está inserida na realidade presente, que a percebe e sobre o qual atua. Nossas percepções e nossas sensações são ao mesmo tempo o que há de mais claro e de mais importante para nós; elas marcam a cada instante a relação variável de nosso corpo com os outros corpos; elas determinam ou orientam nossa conduta. Daí nossa tendência a ver nos outros fatos psicológicos apenas percepções ou sensações obscurecidas ou diminuídas. Aqueles dentre nós que mais resistem a essa tendência, que acreditam perceber no pensamento algo além de um jogo de imagens, têm dificuldade de se persuadir de que a lembrança de uma percepção se distingue radicalmente dessa própria percepção: a lembrança deveria, em todo caso, lhes parece, ser exprimível em termos de percepção, obter-se por alguma operação efetuada sobre a imagem. Qual será então esta operação? A priori, dizemos que ela pode dirigir-se apenas sobre a qualidade do conteúdo da imagem, ou sobre sua quantidade, ou sobre as duas ao mesmo tempo. Ora, não é sobre a qualidade seguramente que ela se dirige, visto que a lembrança deve nos representar o passado sem o alterar. Será, pois, sobre a quantidade. Mas a quantidade, por sua vez, pode ser extensiva ou intensiva, porque a imagem compreende um número determinado de partes, e ela apresenta um certo grau de força. Consideremos a primeira alternativa. A lembrança modifica a extensão da imagem? Não, evidentemente, porque se acrescentasse alguma coisa ao passado, seria infiel, e se dele suprimisse alguma coisa, incompleta. Resta, então, que a modificação diz respeito à intensidade; e como não é evidentemente um aumento, é uma diminuição. Tal é a dialética instintiva, pouco consciente, pela qual somos conduzidos, de eliminação em eliminação, a fazer da lembrança um enfraquecimento da imagem.

Tendo chegado a essa conclusão, toda nossa psicologia da memória nela se inspira e a nossa própria fisiologia é por ela influenciada. De qualquer maneira que nos representemos o mecanismo cerebral da percepção, vemos a lembrança apenas como um novo estímulo do mesmo mecanismo, uma repetição atenuada do mesmo fato. A experiência, entretanto, parece dizer o contrário. Ela nos mostra que se pode perder as lembranças visuais sem deixar de ver e as lembranças auditivas sem deixar de ouvir, que a cegueira e a surdez psíquicas não implicam necessariamente perda da visão e da audição: isso seria possível se a percepção e a memória envolvessem os mesmos centros, colocando em jogo os mesmos mecanismos? Mas passemos adiante, antes de aceitar uma distinção radical entre a percepção e a lembrança.

Por duas vias convergentes, reconstituindo nossa vida psicológica com estados nitidamente divididos e julgando todos esses estados exprimíveis em termos de imagens, o raciocínio acabou por fazer da lembrança uma percepção enfraquecida, alguma coisa que sucede à percepção em vez de 
lhe ser contemporânea. Afastemos essa dialética natural à nossa inteligência, cômoda para a linguagem, indispensável talvez à prática, mas não sugerida pela observação interior: a lembrança aparece como duplicando a todo instante a percepção, nascendo com ela, desenvolvendo-se ao mesmo tempo em que ela e sobrevivendo a ela, precisamente porque ela é de uma outra natureza.

\section{A lembrança do presente}

O que é então a lembrança? Toda descrição clara de um estado psicológico se faz por imagens e acabamos de dizer que a lembrança de uma imagem não é uma imagem. A lembrança pura só poderá, assim, ser descrita de uma maneira vaga, em termos metafóricos. Digamos, pois, como o explicamos em Matière et mémoire, ${ }^{47}$ que a lembrança está para a percepção como a imagem percebida no espelho está para o objeto colocado diante dele. O objeto é tocado tanto quanto é visto; ele age sobre nós como agimos sobre ele; ele está carregado de ações possíveis, ele é atual. A imagem é virtual e, embora semelhante ao objeto, incapaz de fazer o que ele faz. Nossa existência atual, na medida em que se desenvolve no tempo, duplica-se de uma existência virtual, de uma imagem no espelho. Todo momento de nossa vida oferece, pois, dois aspectos: ele é atual e virtual, percepção de um lado e lembrança de outro. Ele se divide ao mesmo tempo em que ocorre. Ou antes, ele consiste nessa própria divisão, porque o instante presente, sempre em marcha, limite fugidio entre o passado imediato que já não é mais e o futuro imediato que não é ainda, se reduziria a uma simples abstração, se não fosse precisamente o espelho móvel que reflete sem cessar a percepção em lembrança.

Imaginemos um espírito que tomasse consciência desse desdobramento. Suponhamos que o reflexo de nossa percepção e de nossa ação nos retorne, não mais quando a percepção está completa e a ação realizada, mas na medida em que percebemos e agimos. Veremos, então, ao mesmo tempo, nossa existência real e sua imagem virtual, o objeto de um lado e o reflexo do outro. O reflexo não se deixará confundir com o objeto, porque este tem todas as características da percepção, aquele já é lembrança: se ele não o fosse desde já, não o seria jamais. Mais tarde, quando desempenhar sua função normal, a lembrança nos representará nosso passado com a marca do passado; percebida no momento em que se forma, é com a marca do passado, constitutiva de sua essência, que ela aparece. Que passado é este? Ele não tem data e não poderia ter; é passado em geral, não pode ser nenhum passado em particular. A rigor, se ele consistisse simplesmente em

47 Cf. todo o primeiro capítulo. 
um certo espetáculo percebido, em uma certa emoção experimentada, poder-se-ia iludir-se, e crer que já se percebeu o que se percebe, experimentou o que se experimenta. Mas trata-se efetivamente de outra coisa. O que se desdobra a cada instante em percepção e em lembrança é a totalidade do que vemos, ouvimos, experimentamos, tudo o que somos com tudo o que nos cerca. Se tomarmos consciência desse desdobramento, é a integralidade de nosso presente que nos aparecerá ao mesmo tempo como percepção e como lembrança. E, todavia, bem sabemos que não se vive duas vezes o mesmo momento de uma história e que o tempo não refaz seu curso. O que fazer? A situação é estranha, paradoxal. Ela perturba todos os nossos hábitos. Uma lembrança está aí: é uma lembrança, porque traz a marca característica dos estados que chamamos comumente por esse nome e que só se esboçam na consciência uma vez que seu objeto tenha desaparecido. E, todavia, não nos representa alguma coisa que foi, mas simplesmente alguma coisa que é; ela marcha pari passu com a percepção que ela reproduz. É, no momento atual, uma lembrança desse momento. É o passado quanto à forma e o presente quanto à matéria. É uma lembrança do presente.

Na medida em que a situação progride, a lembrança, que está ao lado dela, dá a cada uma das etapas o aspecto do "déjà vu", do já conhecido. Mas esta situação, mesmo antes de ter chegado a seu termo, parece formar um todo, sendo recortada na continuidade de nossa experiência pelo interesse do momento. Como teríamos já vivido uma parte da situação se não tivéssemos vivido o seu todo? Reconheceríamos o que se desenrola se não conheCêssemos o que está ainda enrolado? Não estamos na situação, pelo menos, de antecipar a cada momento o momento seguinte? O instante que virá já está penetrado pelo instante presente; o conteúdo do primeiro é inseparável do conteúdo do segundo: se um é um recomeço de meu passado, e não se pode duvidar disso, como o instante seguinte também não o seria? Reconheço lá, reconhecerei pois seguramente aqui. Assim me encontro sem cessar, frente ao que está para acontecer, na atitude de uma pessoa que reconhecerá, e que, por conseguinte, conhece. Mas esta é apenas a atitude do conhecimento; é a sua forma sem a matéria. Como não posso predizer o que acontecerá, vejo bem que não o sei; mas prevejo que o terei sabido, no sentido de que o reconhecerei, percebendo-o; e este reconhecimento por vir, que sinto inevitável em virtude do élan apreendido minuciosamente por minha faculdade de reconhecer, exerce de antemão um efeito retroativo sobre meu presente, colocando-me na estranha situação de uma pessoa que sente conhecer o que sabe ignorar.

\section{O desdobramento do presente}

Suponha que nos surpreendamos a repetir maquinalmente uma lição outrora sabida de cor e agora esquecida. Como se reconhece cada palavra 
pronunciada, sente-se que se a possuía antes de a pronunciar, e, todavia, se a reencontra somente em a pronunciando. Aquele que tomar consciência do desdobramento contínuo de seu presente em percepção e em lembrança estará na mesma condição. Por pouco que analise a si mesmo, comparar-seá ao ator que desempenha automaticamente o seu papel, escutando-se e vendo-se atuar. Quanto mais ele aprofunda o que experimenta, mais se divide em dois personagens, dos quais um se oferece em espetáculo ao outro. Ele sabe que continua a ser o que era, um eu que pensa e que age conforme a situação exige, um eu inserido na vida real e se adaptando a ela por um livre esforço de sua vontade: eis o que sua percepção do presente lhe assegura. Mas a lembrança desse presente, que está igualmente aí, lhe faz crer que ele repete integralmente as coisas já ditas, que ele revê exatamente as coisas já vistas, e o transforma assim em ator que desempenha um papel. Daí dois eus diferentes, dos quais um, consciente de sua liberdade, se erige em espectador independente de uma cena que o outro desempenharia de uma maneira maquinal. Mas esse desdobramento não chega jamais ao fim. É antes uma oscilação da pessoa entre dois pontos de vista sobre ela mesma, um vai e vem do espírito entre a percepção, que é apenas percepção, e a percepção duplicada com sua própria lembrança: a primeira envolve o sentimento habitual que temos de nossa liberdade e se insere naturalmente no mundo real; a segunda nos faz crer que repetimos um papel aprendido, nos converte em autômatos, nos transporta para um mundo de teatro ou de sonho. Quem quer que tenha passado por um grande perigo durante alguns instantes, ao qual só pôde escapar por uma série rápida de passos tão imperiosamente necessários quanto livremente realizados, experimentou alguma coisa do mesmo gênero. É um desdobramento mais virtual do que real. Age e todavia "sofre ação". Sente que escolhe e que quer, mas que escolhe o que é imposto e que quer o inevitável. Daí uma compenetração de estados que se fundem e mesmo se identificam conjuntamente na consciência imediata, mas que não são menos logicamente incompatíveis entre si e que a consciência reflexiva representará por um desdobramento do eu em dois personagens diferentes, dos quais um tomaria para si tudo o que é liberdade, enquanto que o outro guardaria para si a necessidade - aquele, espectador livre, olhando este desempenhar seu papel automaticamente.

Acabamos de descrever os três principais aspectos sob os quais nos apareceríamos a nós mesmos, no estado normal, se pudéssemos assistir à divisão de nosso presente. Ora, esses são precisamente os caracteres do falso reconhecimento. Eles são mais acentuados, na medida em que o fenômeno é mais nítido, mais completo, mais profundamente analisado por quem o experimentou.

Muitos falam de um sentimento de automatismo e de um estado comparável ao do ator que desempenha um papel. O que diz e o que faz, o que 
diz e o que faz em si mesmo, parece "inevitável". Assiste-se aos próprios movimentos, pensamentos e ações. ${ }^{48}$ As coisas se passam como se se desdobrassem, sem, todavia, desdobrarem-se efetivamente. Um dos sujeitos escreve: "Este sentimento de desdobramento existe apenas na sensação; as duas pessoas são apenas uma do ponto de vista material". ${ }^{9}$ Por essa afirmação, ele entende, sem dúvida, que experimenta um sentimento de dualidade, mas acompanhado da consciência de que se trata de uma só e mesma pessoa.

Mas, como dizíamos no início, o sujeito encontra-se freqüentemente no singular estado de alma de uma pessoa que acredita saber o que vai acontecer, sentindo-se incapaz de o predizer. "Parece sempre, diz um deles, que vou prever o que se segue, mas que não poderei o anunciar realmente." Um outro lembra o que vai acontecer "como se se lembrasse de um nome que está na borda da memória". ${ }^{50}$ Uma das mais antigas observações é a de um doente que se imagina antecipar tudo o que acontecerá à sua volta. ${ }^{51}$ Eis, pois, uma outra característica do falso reconhecimento.

Mas, a mais geral de todas é aquela da qual falávamos no início: a lembrança evocada é uma lembrança suspensa no ar, sem ponto de apoio no passado. Ela não corresponde a qualquer experiência anterior. Sabe-se dela, esta-se convencido disso e tal convicção não é o efeito de um raciocínio: ela é imediata. Ela se confunde com o sentimento de que a lembrança evocada deve ser simplesmente um duplicatum da percepção atual. Ela é, então, uma "lembrança do presente"? Se não foi dito isso, é porque, sem dúvida, a expressão pareceria contraditória, porque não se concebe a lembrança de outro modo que uma repetição do passado, porque não se admite que uma representação possa trazer a marca do passado independentemente daquilo que ela representa, enfim, porque se é teórico sem o saber e porque se considera que toda lembrança é posterior à percepção que reproduz. Mas diz-se alguma coisa parecida, fala-se de um passado que nenhum intervalo separaria do presente: "Senti produzir-se em mim uma espécie de separação que suprimiu todo o passado entre este minuto de outrora e o minuto no qual eu me encontrava". ${ }^{52}$ Aí está efetivamente a característica do fenômeno. Quando se fala de "falso reconhecimento", dever-se-ia especificar que não se trata de um processo que simula o reconhecimento verdadeiro, que não se trata de uma ilusão dele. O que é, em efeito, o reconheci-

\footnotetext{
48 Ver, em particular, as observações recolhidas por Bernard-Leroy, op.cit., p.182, p.185, p.176, p.232, etc.

49 Ibid, p.186.

50 Lalande, Des paramnésies, Rev. Philos., vol. XXXVI, 1893, p.487.

51 Jensen, art. cit., p.57.

52 F. Gregh, citado por Bernard-Leroy, p.183.
} 
mento normal? Ele pode produzir-se de duas maneiras, seja por um sentimento de familiaridade que acompanha a percepção presente, seja pela evocação de uma percepção passada que a percepção presente parece repetir. Ora, o falso reconhecimento não é nem uma nem outra dessas duas operações. O que caracteriza o reconhecimento do primeiro gênero é o fato de excluir toda lembrança de uma situação determinada, pessoal, na qual o objeto reconhecido teria já sido percebido. Meu gabinete de trabalho, minha mesa, meus livros compõem em torno de mim uma atmosfera de familiaridade somente com a condição de não fazer surgir a lembrança de nenhum evento determinado de minha história. Se eles evocam a lembrança precisa de um incidente ao qual se misturaram, ainda os reconheço como tendo tomado parte dele, mas esse reconhecimento se acrescenta ao primeiro e dele se distingue profundamente, como o pessoal se distingue do impessoal. Ora, o falso reconhecimento é algo diferente desse sentimento de familiaridade. Refere-se sempre a uma situação pessoal, sobre a qual se está convencido de que ela reproduz uma outra situação pessoal, tão precisa e tão determinada quanto ela.

Resta saber se ele é o reconhecimento do segundo gênero, aquele que implica a lembrança de uma situação semelhante àquela em que se encontra atualmente. Mas observemos que se trata, sempre, em tal caso, de situações semelhantes e não de situações idênticas. O reconhecimento do segundo gênero se faz apenas pela representação do que diferencia as duas situações ao mesmo tempo antes do que pelo que lhes é comum. Se assisto pela segunda vez a uma comédia, reconheço uma a uma cada uma das palavras, cada uma das cenas, reconheço, enfim, toda a peça e me lembro de a ter já visto; mas eu estava então em um outro lugar, eu tinha outros vizinhos, eu tinha outras preocupações; de todo modo, eu não podia ser então o que sou hoje, visto que continuei vivendo nesse intervalo. Se, pois, as duas imagens são as mesmas, elas não se apresentam no mesmo quadro, e o vago sentimento da diferença dos quadros cerca, como uma franja, a consciência que tenho da identidade das imagens e me permite a todo instante as distinguir. Ao contrário, no falso reconhecimento, os quadros são idênticos, como as próprias imagens. Assisto ao mesmo espetáculo com as mesmas sensações, as mesmas preocupações: em suma, estou neste momento no mesmo ponto, na mesma data, no mesmo instante, em que me encontrava então em minha história. Dificilmente se pode falar aqui de ilusão, visto que o conhecimento ilusório é a imitação de um conhecimento real, e o fenômeno ao qual nos referimos não imita nenhum outro fenômeno de nossa experiência. E dificilmente se pode falar de falso reconhecimento, visto que não há reconhecimento verdadeiro, de um gênero ou de outro, do qual este seria a exata imitação. Em realidade, trata-se de um fenômeno único em seu gênero, o mesmo que seria produzido pela "lembrança do pre- 
sente", se ela surgisse repentinamente do inconsciente onde deve permanecer. Ele pareceria uma lembrança, visto que a lembrança oferece uma marca distintiva, diferente daquela da percepção; mas ele não poderia ser relacionado a uma experiência passada, porque cada um de nós sabe bem que não se vive duas vezes o mesmo momento de sua história.

\section{Por que o desdobramento é inconsciente?}

Resta saber por que essa lembrança permanece ordinariamente oculta, e como ela se revela em casos extraordinários. De uma maneira geral, de direito, o passado somente volta à consciência na medida em que pode ajudar a compreender o presente e prever o futuro: é um esclarecedor da ação. Trilha-se o caminho errado, quando se estudam as funções da representação em estado isolado, como se elas fossem em si mesmas seu próprio fim, como se fôssemos puros espíritos, ocupados em ver passar idéias e imagens. A percepção presente atrairia, então, a si uma lembrança similar, sem nenhum pensamento dissimulado de utilidade, por nada, por prazer - pelo prazer de introduzir no mundo mental uma lei de atração análoga àquela que governa o mundo dos corpos. Não contestamos certamente "a lei de semelhança", mas, como observamos em outro lugar, duas idéias quaisquer e duas imagens tomadas ao acaso, por mais distantes que se as suponha, assemelhar-se-ão sempre em algum aspecto, visto que se encontrará sempre um gênero comum onde as fazer entrar: de sorte que qualquer percepção evocaria qualquer lembrança, se houvesse apenas uma atração mecânica do semelhante pelo semelhante. A verdade é que, se uma percepção evoca uma lembrança, é porque as circunstâncias que precederam, acompanharam e seguiram a situação passada lançam alguma luz sobre a situação atual e mostram uma saída para ela. Milhares e milhares de evocações de lembranças por semelhança são possíveis, mas a lembrança que tende a reaparecer é a que se assemelha à percepção em um certo aspecto particular, aquela que pode esclarecer e dirigir o ato em preparação. E esta própria lembrança poderia, a rigor, não se manifestar: bastaria que ela evocasse, sem se mostrar a si própria, as circunstâncias que foram dadas em contigüidade com ela, o que a precedeu e o que a seguiu, enfim, o que importa conhecer para compreender o presente e antecipar o futuro. Conceber-se-ia mesmo que nada de tudo isso se manifestasse à consciência e que apenas a conclusão aparecesse, isto é, a sugestão precisa do passo a ser dado. Provavelmente é assim que as coisas se passam com a maior parte dos animais. Quanto mais a consciência se desenvolve, mais ela esclarece a operação da memória e mais também ela deixa transparecer a associação por semelhança, que é o meio, por trás da associação por contigüidade, que é o 
fim. Aquela, uma vez instalada na consciência, permite a uma multidão de lembranças de luxo se apresentar em virtude de alguma semelhança, mesmo que desprovidas de interesse atual: assim se explica que possamos sonhar um pouco ao agir; mas são as necessidades da ação que determinam as leis da evocação; somente elas detêm as chaves da consciência, e as lembranças do sonho apenas se introduzem aproveitando o que há de frouxo, de mal definido, na relação de semelhança que autoriza a sua entrada. Em suma, se a totalidade de nossas lembranças exerce a todo instante uma pressão do fundo do inconsciente, a consciência atenta à vida só deixa passar, legalmente, aquelas que podem concorrer para a ação presente, embora muitas outras se insinuem graças a essa condição geral de semelhança que é preciso supor.

Mas o que há de mais inútil à ação presente do que a lembrança do presente? Todas as outras lembranças também reivindicariam os seus direitos, porque elas, pelo menos, trazem consigo alguma informação, mesmo que não tenham interesse atual. Sozinha, a lembrança do presente não tem nada a nos ensinar, sendo apenas o duplo da percepção. Temos o objeto real: que faríamos com a imagem virtual? Seria o mesmo que trocar o certo pelo duvidoso.

Eis por que não é da lembrança que nossa atenção se desvia mais obstinadamente.

Não se trata aqui da atenção individual cuja intensidade, direção e duração mudam conforme as pessoas. É, poder-se-ia dizer, a atenção da espécie, uma atenção naturalmente voltada para certas regiões da vida psicológica, naturalmente desviada das outras. No interior de cada uma dessas regiões, nossa atenção individual dirigir-se-á sem dúvida à sua fantasia, mas ela virá, simplesmente, então, sobrepor-se à atenção da espécie, como a escolha que o olho individual faz de tal ou qual objeto para o olhar se sobrepõe àquela que o olho humano fez, de uma vez por todas, de uma certa região determinada do espectro para nele ver a luz. Ora, se uma leve diminuição da atenção individual é apenas a distração normal, toda fraqueza da atenção da espécie se traduz pelos fatos patológicos ou anormais.

\section{Desatenção à vida}

O falso reconhecimento é uma dessas anomalias. Ele envolve um enfraquecimento temporário da atenção geral à vida: o olhar da consciência, não mais se mantendo em sua direção natural, deixa-se distrair e considerar o que não tem nenhum interesse para se perceber. Mas o que se deve entender aqui por "atenção à vida"? Qual é o gênero especial de distração que culmina no falso reconhecimento? Atenção e distração são termos vagos: pode-se defini-los mais precisamente nesse caso particular? Tentaremos 
fazê-lo, sem pretender, entretanto, alcançar, em um assunto tão obscuro, uma clareza completa e uma precisão definitiva.

Não foi suficientemente considerado que nosso presente é, sobretudo, uma antecipação de nosso futuro. A visão que nossa consciência reflexiva nos dá de nossa vida interior é, sem dúvida, a de um estado sucedendo a outro estado, cada um destes estados começando em um ponto, terminando em um outro, e se bastando provisoriamente a si mesmo. Assim o quer a reflexão, que prepara as vias para a linguagem; ela distingue, afasta e justapõe; ela está à vontade apenas no definido e no imóvel; ela se detém em uma concepção estática da realidade. Mas a consciência imediata apreende algo muito diferente. Imanente à vida interior, ela mais a sente do que a vê; mas ela a sente como um movimento, como uma invasão contínua de um futuro que recua sem cessar. Este sentimento se torna, aliás, muito claro quando se trata de um ato que nos propomos a realizar. O termo da operação nos aparece imediatamente e, durante todo o tempo em que agimos, temos menos consciência de nossos estados sucessivos do que de um afastamento decrescente entre a posição atual e o termo do qual nos aproximamos. Aliás, este próprio fim é percebido apenas como um fim provisório; sabemos que há outra coisa atrás dele; no élan que tomamos para transpor o primeiro obstáculo, já nos preparamos para saltar um segundo, aguardando os outros que se sucederão indefinidamente. Do mesmo modo, quando escutamos uma frase, não é preciso que prestemos atenção às palavras isoladamente: é o sentido do todo que nos importa; desde o início reconstruímos esse sentido hipoteticamente; lançamos nosso espírito em uma certa direção geral, deixado a inflectir diversamente esta direção na medida em que a frase, desenrolando-se, encaminhe nossa atenção em um sentido ou em outro. Aqui, ainda, o presente é percebido no futuro que ele invade, mais que apreendido em si mesmo. Esse élan dá a todos os estados psicológicos que ele atravessa ou transpõe um aspecto particular, mas tão constante que quando ele falta percebemos a sua ausência, bem mais que sua presença à qual estamos acostumados. Cada um de nós já pôde observar o caráter estranho que adquire, às vezes, uma palavra familiar, quando prestamos atenção a ela. A palavra aparece como se fosse nova, e ela de fato o é; jamais, até aí, nossa consciência tinha feito dela um ponto de parada; ela a atravessava para chegar ao fim de uma frase. Não nos é tão fácil comprimir o élan de nossa vida psicológica inteira como no caso de nossa palavra; mas, quando o élan geral enfraquece, a situação transposta deve parecer tão bizarra quanto o som de uma palavra que se imobiliza no curso do movimento da frase. Ele não mais adere à vida real. Procurando, entre nossas experiências passadas, a que mais lhe parece, é com o sonho que nós a compararemos.

Ora, é preciso observar que a maior parte dos sujeitos, descrevendo o que experimenta durante e após o falso reconhecimento, fala de uma impres- 
são de sonho. A ilusão é acompanhada "de uma espécie de sentimento não analisável de que a realidade é um sonho", diz M.Paul Bourget. ${ }^{53}$ Em uma auto-observação redigida em inglês, a qual me foi enviada há alguns anos, encontro o epíteto shadowy aplicado ao conjunto do fenômeno; acrescenta-se que o fenômeno se apresenta mais tarde, quando se o rememora, como the half forgotten relic of a dream. Observadores que não se conhecem, que falam línguas diferentes, exprimem-se em termos que são a tradução textual uns dos outros. A impressão de sonho é, pois, mais ou menos geral.

Mas é preciso observar também que as pessoas sujeitas ao falso reconhecimento são freqüentemente levadas a achar estranha uma palavra familiar. Uma investigação feita por G. Heymans lhe mostrou que essas duas disposições estavam ligadas uma à outra. ${ }^{54} \mathrm{O}$ autor acrescenta, com razão, que as teorias correntes do primeiro fenômeno não explicam porque ele se associa ao segundo.

\section{A insuficiência do Élan}

Nessas condições, não se pode procurar a causa inicial do falso reconhecimento em uma suspensão momentânea de nosso élan de consciência, suspensão que não muda nada, sem dúvida, na materialidade de nosso presente, mas o separa do futuro ao qual está intimamente ligado e da ação que seria a sua conclusão normal, dando-lhe assim o aspecto de um simples quadro, de um espetáculo que se oferece a si mesmo, de uma realidade transposta em sonho? Permitam-me descrever uma impressão pessoal. Não experienciamos o fenômeno do falso reconhecimento, mas temos tentado, muito freqüentemente, desde que o estudamos, nos colocar no estado de alma descrito pelos observadores e induzi-lo experimentalmente em nós. Nunca o conseguimos completamente; obtivemos, todavia, várias vezes, algo de aproximado, mas muito fugidio. Foi preciso para isso que nos encontrássemos em presença de uma cena, não somente nova para nós, mas que sobressai do curso de nossa vida habitual. Por exemplo, um espetáculo ao qual assistimos em viagem, sobretudo se a viagem foi improvisada. A primeira condição é, então, que experimentemos um certo espanto particular, que eu chamaria de o espanto de se encontrar ali. Sobre esse espanto, vem se enxertar um sentimento muito diferente, que tem, todavia, um parentesco com ele: o sentimento de que o futuro está fechado, que a situação está destacada do todo, mas que estamos ligados a ela. À medida que essas

53 Observação colhida por M.Bernard Leroy, op.cit., p.169.

54 Zeitschr. F. Psychologie, vol. 36, 1904, pp.321-343; e vol. 43, 1906, pp.1-17. 
duas emoções se compenetram, a realidade perde sua solidez e nossa percepção do presente tende também a se duplicar de alguma outra coisa, que estaria por detrás. É a "lembrança do presente" que transparece? Não o ousaríamos afirmar, mas parece que estamos no caminho do falso reconhecimento e que haveria pouca coisa a fazer para nele se chegar.

Agora, por que a lembrança do presente espera, para se revelar, que o élan de consciência se enfraqueça ou seja suspenso? Não sabemos nada sobre o mecanismo pelo qual uma representação sai do inconsciente ou a ele retorna. Tudo o que podemos fazer é recorrer a um esquema provisório para simbolizar a operação. Retornemos àquele do qual nos servimos no início. Representemo-nos a totalidade das lembranças inconscientes como pressionando a consciência - esta deixando passar, em princípio, apenas o que pode concorrer para a ação. A lembrança do presente esforça-se como as outras; aliás, ela está mais próxima de nós que as outras; inclinada sobre nossa percepção do presente, ela está sempre a ponto de nela entrar. A percepção escapa, apenas em virtude do movimento contínuo para frente, o qual mantém o afastamento. Em outros termos, uma lembrança somente se atualiza por intermédio de uma percepção: a lembrança do presente penetraria, pois, na consciência, se ela pudesse se insinuar na percepção do presente. Mas esta está sempre à frente daquela: graças ao élan que a anima, ela está menos no presente que no futuro. Suponhamos que, de repente, o élan seja suspenso: a lembrança junta-se à percepção, o presente é reconhecido ao mesmo tempo em que é conhecido.

O falso reconhecimento seria, pois, a forma mais inofensiva de desatenção à vida. Uma redução constante do tom da atenção fundamental se traduziria por problemas psicológicos mais ou menos profundos e duráveis. Mas pode acontecer que esta atenção se mantenha ordinariamente em seu tom normal e que sua insuficiência se manifeste de uma maneira totalmente diferente; por suspensões do funcionamento, geralmente muito curtas, espaçadas de tempos em tempos. Desde que haja a suspensão, o falso reconhecimento atinge a consciência, recobre-a durante alguns instantes e cai imediatamente, como uma onda.

Concluamos com uma última hipótese, que pressentimos desde o início de nosso trabalho. Se a desatenção à vida pode adquirir duas formas desigualmente graves, não se está no direito de supor que a segunda, mais benigna, é um meio de se preservar da outra? Quando uma insuficiência de atenção corre o risco de se traduzir por uma passagem definitiva do estado de vigília ao estado do sonho, a consciência localiza o mal em alguns pontos aos quais ela dirige a atenção com súbitas interrupções: a atenção poderá, assim, manter-se, todo o resto do tempo, em contato com a realidade. Alguns casos muito claros de falso reconhecimento confirmariam esta hipótese. O sujeito sente-se inicialmente separado do todo, como em um sonho: 
logo após, acontece o falso reconhecimento, quando ele começa a reapoderar-se de si mesmo. ${ }^{55}$

Seria, pois, a perturbação da vontade que ocasionaria o falso reconhecimento. Ela seria, de fato, sua causa inicial. Quanto à causa próxima, ela deve ser procurada em outro lugar, no jogo combinado da percepção e da memória. O falso reconhecimento resulta do funcionamento natural dessas duas faculdades entregues a si mesmas. Ele aconteceria a todo instante, se a vontade, incessantemente tensa para a ação, não impedisse o presente de retornar sobre si mesmo impulsionando-o indefinidamente para o futuro. $\mathrm{O}$ élan de consciência, que é uma manifestação do élan da vida, escapa à análise em virtude de sua simplicidade. Pelo menos pode-se estudar, nos momentos em que ele torna-se mais fraco, as condições do equilíbrio móvel que ele havia até então mantido e analisar, assim, uma manifestação na qual transparece sua essência.

Tradução recebida em 06/05; aprovada para publicação em 01/06.

55 Ver, em particular, as auto-observações de Kraepelin e de MM.Dormard e Albès, art. cit. 